\title{
Genetic predictors of thiazide-induced serum potassium changes in nondiabetic hypertensive patients
}

\author{
Chin-Chou Huang ${ }^{1,2,3,4}$, Chia-Min Chung, ${ }^{5,6}$, Shuen-Iu Hung ${ }^{4}$, Hsin-Bang Leu ${ }^{2,3,7,8}$, Liang-Yu Lin ${ }^{9}$, \\ Po-Hsun Huang ${ }^{2,3,8}$, Tao-Cheng $\mathrm{Wu}^{2,3,8}$, Shing-Jong Lin ${ }^{1,2,3,8}$, Wen-Harn Pan ${ }^{10,11}$ and Jaw-Wen Chen ${ }^{1,2,3,4}$
}

Thiazide diuretics are associated with an increased risk of hypokalemia. However, pharmacogenetic markers of thiazide-induced changes in serum potassium are not well studied. The aim of this study was to investigate possible predictors of serum potassium changes after thiazide treatment. Nondiabetic hypertensive patients with a systolic blood pressure of $\geqslant 140$ or a diastolic blood pressure of $\geqslant 90 \mathrm{~mm} \mathrm{Hg}$ were enrolled in our study. After 2 weeks of lifestyle modification and diet instruction, patients with persistently elevated blood pressure were given $50 \mathrm{mg}$ of hydrochlorothiazide every morning for 2 weeks. Twenty single-nucleotide polymorphism (SNP) markers were selected from two candidate genes, SLC12A3 and WNK1. Serum potassium levels were checked before and after hydrochlorothiazide treatment. A total of 75 patients eventually qualified for enrollment in our study. They received $50 \mathrm{mg}$ of hydrochlorothiazide every morning for 2 weeks. Six SNPs in WNK1 (rs11064524, rs4980973, rs12581940, rs880054, rs953361, and rs10849582) were correlated with decreases in serum potassium. None of the SLC12A3 polymorphisms were correlated with decreases in serum potassium. After Bonferroni's correction, only rs 4980973 was correlated with decreases in serum potassium (corrected $P=0.014$ ). Multivariate stepwise linear regression analysis revealed that the changes in serum potassium levels were independently associated with the baseline potassium level $(\beta=-0.587,95 \%$ confidence interval $=-0.875--0.299, P=0.0001)$ and $W N K 1 \mathrm{rs} 4980973(\mathrm{~A} / \mathrm{A}$ and $\mathrm{A} / \mathrm{G}$ vs. $\mathrm{G} / \mathrm{G}, \boldsymbol{\beta}=-0.418,95 \%$ confidence interval $=-0.598-0.237, P=0.00002)$. In conclusion, the baseline potassium level and the WNK1 rs 4980973 polymorphism were independent predictors of decreases in serum potassium after short-term hydrochlorothiazide treatment in nondiabetic hypertensive patients.

Hypertension Research (2014) 37, 759-764; doi:10.1038/hr.2014.74; published online 3 April 2014

Keywords: hydrochlorothiazide; hypokalemia; single-nucleotide polymorphism; thiazide

\section{INTRODUCTION}

Antihypertensive treatment with thiazide-type diuretics has conferred significant reductions in stroke and cardiovascular events by lowering blood pressure (BP) in hypertensive patients. ${ }^{1-5}$ However, electrolyte imbalance is a common complication following thiazide treatment. ${ }^{6-8}$ In recent years, it has become clear that electrolyte disorders, even if they are chronic and mild, are associated with adverse outcomes. ${ }^{8-11}$ The presence of hypokalemia on admission has been associated with higher in-hospital mortality. ${ }^{8}$ A recent study in patients with myocardial infarction also found increased mortality among patients with hypokalemia, supporting other findings on the negative effects of dyskalemia on outcomes. ${ }^{12}$
Although thiazide diuretics are associated with an increased risk of hypokalemia, pharmacogenetic markers of thiazide-induced changes in serum potassium are not well studied. When considering dyskalemia, Gitelman's syndrome and Gordon syndrome are two classic genetic disorders of electrolyte imbalance. Gitelman's syndrome is an autosomal recessive salt-losing tubulopathy. It is caused by mutations in the SLC12A3 gene encoding the thiazide-sensitive Na-Cl cotransporter (NCC). ${ }^{13-16}$ The syndrome is characterized by hypokalemic alkalosis, hypomagnesemia and hypocalciuria that are similar to the side effects of the chronic administration of thiazide diuretics. In contrast, Gordon syndrome (or pseudohypoaldosteronism type 2 (PHA2)) is an autosomal dominant disease. It is caused by mutations

${ }^{1}$ Department of Medical Research and Education, Taipei Veterans General Hospital, Taipei, Taiwan, Republic of China; ${ }^{2}$ Division of Cardiology, Department of Medicine, Taipei Veterans General Hospital, Taipei, Taiwan, Republic of China; ${ }^{3}$ Cardiovascular Research Center, National Yang-Ming University, Taipei, Taiwan, Republic of China; ${ }^{4}$ Institute of Pharmacology, National Yang-Ming University, Taipei, Taiwan, Republic of China; ${ }^{5}$ Environment-Omics-Disease Research Centre, China Medical University Hospital, Taichung, Taiwan, Republic of China; ${ }^{6}$ Graduate Institute of Clinical Medical Science, China Medical University, Taichung, Taiwan, Republic of China; ${ }^{7}$ Healthcare and Management Center, Taipei Veterans General Hospital, Taipei, Taiwan, Republic of China; ${ }^{8}$ Institute of Clinical Medicine, National Yang-Ming University, Taipei, Taiwan, Republic of China; ${ }^{9}$ Division of Endocrinology and Metabolism, Department of Medicine, Taipei Veterans General Hospital, Taipei, Taiwan, Republic of China; ${ }^{10}$ Institute of Biomedical Sciences, Academia Sinica, Taipei, Taiwan, Republic of China and ${ }^{11}$ Institute of Epidemiology, School of Public Health, National Taiwan University, Taipei, Taiwan, Republic of China

Correspondence: Dr J-W Chen, Department of Medical Research and Education, Taipei Veterans General Hospital, No. 201, Section 2, Shih-Pai Road, Taipei, Taiwan, Republic of China. 
in NCC regulators with no-lysine kinase 1 (WNK1) and WNK4. ${ }^{17}$ The syndrome is characterized by an early onset of hypertension and hyperkalemia. The phenotype is the opposite of Gitelman's syndrome and is effectively reversed by a low dose of thiazide diuretics. It would be interesting to determine whether the polymorphisms in the SLC12A3 and WNK1 genes are related to the electrolyte imbalance that develops following the administration of thiazide diuretics to hypertensive patients.

Given the clinical recommendation of thiazide diuretics, particularly for elderly hypertensives and people with resistant hypertension, the development of thiazide-induced electrolyte imbalances, such as hypokalemia, should be monitored carefully. However, clinical information regarding which patients are more susceptible to thiazide-induced hypokalemia is lacking and the impact of genetic factors is not known. This study aimed to investigate the potential clinical and genetic predictors of serum potassium decreases following treatment with thiazide diuretics. Because the causes of electrolyte imbalances such as hypokalemia may be complicated clinically, we could only evaluate the direct causal relationship of thiazide-induced hypokalemia through short-term thiazide treatment. Given the increasing interest in personalized medicine, our findings could provide novel rationales for optimizing the use of thiazide diuretics on an individualized basis.

\section{METHODS}

\section{Study population}

A series of consecutive patients with essential hypertension were prospectively included in the study if all the following criteria were fulfilled: (1) age between 25 and 65 years; (2) sitting office systolic BP (SBP) of 140-180 mm Hg and/or sitting diastolic BP (DBP) of $90-110 \mathrm{~mm} \mathrm{Hg}$ on three different occasions within a period of 3 months, or currently on $\geqslant 1$ antihypertensive medications without any diuretics; (3) fasting plasma sugar $<126 \mathrm{mg} \mathrm{dl}^{-1}$; and (4) no evidence of secondary hypertension through serial studies including blood chemistry, renal function tests, endocrine examination, abdominal sonogram and/or renal arteriogram, among others, to exclude the possibility of chronic renal disease, renal arterial stenosis, primary aldosteronism, Cushing syndrome, pheochromocytoma, thyroid disorder and coarctation of the aorta. Patients with the following characteristics were excluded: (1) a history of diabetes mellitus; (2) a history of major systemic disease within the past 3 months; (3) body mass index $>30 \mathrm{~kg} \mathrm{~m}^{-2}$; (4) renal dysfunction with a plasma creatinine level $>1.7 \mathrm{mg} \mathrm{dl}^{-1}$; (5) liver dysfunction with liver enzymes $>2$ times the normal upper limit; (6) congestive heart failure with New York Heart Association function class II-IV; and (7) pregnant women.

All patients were first evaluated at the hypertension clinic of the hospital. A hypertension specialist took a comprehensive history and conducted a physical check-up. Patients underwent a series of tests including office BP, body mass index, waist and hip circumference and blood sampling. The patients were first observed while following their regular cardiovascular medications, if there were any, for 2 weeks. Then, the patients were interviewed again and monitored for their daily lifestyle and eating habits. If their rechecked BP was $\geqslant 140 / 90 \mathrm{~mm} \mathrm{Hg}$, the patients were assigned to take $50 \mathrm{mg}$ of hydrochlorothiazide (HCTZ) once every morning in addition to their usual medications, if they had any, for the next 2 weeks. Blood sampling and sitting office BP were repeated, followed by a comprehensive history and physical check-up. The ethics committee of the hospital approved the study protocol. All the patients agreed to participate after being informed of the nature and purpose of the study. This study was conducted in accordance with the principles of the Declaration of Helsinki and Title 45, US Code of Federal Regulations, Part 46, Protection of Human Subjects, Revised 13 November 2001, effective 31 December 2001.

\section{BP measurement}

At each visit, $\mathrm{BP}$ was measured on the nondominant upper arm by the same well-trained nurse using a validated automatic digital BP monitor (Omron
HEM-780, Lake Forest, IL, USA). This was performed in the morning hours, after sitting for $10 \mathrm{~min}$ in a quiet room. Three consecutive BP measurements were performed each time. Each measurement was separated by a 30-s pulse measurement. The recorded BP was the average value of the last two recordings.

\section{Laboratory measurements}

Venous blood was collected by phlebotomy from fasting participants who rested supine for $\sim 10 \mathrm{~min}$, typically between 0730 and $0900 \mathrm{~h}$. Serum sodium and potassium were measured using standard methods at baseline and after 2 weeks of HCTZ treatment. Baseline plasma renin activity was determined using kits from DiaSorin (Stillwater, MN, USA; Gamma-Coat PRA 125I RIA Kit). Baseline plasma aldosterone was measured using a radioimmunoassay (Quest Diagnostics, Madison, NJ, USA). ${ }^{18}$ Baseline serum angiotensin-converting enzyme activity was measured using the Quantikine Human ACE Immunoassay (R\&D Systems, Minneapolis, MN, USA). ${ }^{19}$ The people performing the above tests were blinded to the clinical data of the study subjects.

\section{Selection of candidate genes}

This study evaluated two candidate genes: SLC12A $3^{13-16}$ and WNK1. ${ }^{17,20} \mathrm{We}$ searched for single-nucleotide polymorphisms (SNPs) in these genes in the NCBI SNP Database (http://www.ncbi.nlm.nih.gov/SNP/) and selected SNPs with a minor allele frequency of $>0.05$ as the genotyping markers. We investigated $7 \mathrm{SNP}$ markers in the introns of the SLC12A3 gene (rs2304483, rs2278490, rs13306679, rs2289114, rs4567697, rs2399594 and rs711747) and 13 SNP markers in the introns of the WNK1 gene (rs11064524, rs2107614, rs765250, rs1159744, rs2286007, rs4980973, rs12581940, rs880054, rs956868 rs953361, rs2301880, rs10849582 and rs2286028). Figure 1 shows the linkage disequilibrium plots of SLC12A3 and WNK1. These SNPs had a P-value of Hardy-Weinberg equilibrium $>0.01$.

\section{Genotyping}

A total of $20 \mathrm{ml}$ of blood was collected from each patient. We isolated the genomic DNA of the patients from peripheral lymphocytes using the phenol/ chloroform extraction method. SNP genotyping was performed using high-throughput MALDI-TOF (matrix-assisted laser desorption and ionization-time of flight) mass spectrometry. Briefly, primers and probes were designed using SpectroDESIGNER software (Sequenom, San Diego, CA, USA) Multiplex PCRs were performed, and unincorporated ddNTPs were dephosphorylated using shrimp alkaline phosphatase (Hoffman-LaRoche, Basel, Switzerland), followed by primer extension. The purified primer extension reaction was spotted onto a 384-element silicon chip (Spectro-CHIP, Sequenom) and analyzed using an autoflex MALDI-TOF SpectroREADER mass spectrometer (Sequenom); the resulting spectra were processed with SpectroTYPER (Sequenom). The people performing the genetic study were blinded to the clinical data of the study subjects.

\section{Statistical analysis}

All data were expressed as the frequency (percentage) or mean \pm s.d. or median with interquartile ranges. Plasma renin activity and aldosterone levels were natural-log transformed because of their positively skewed distribution. We analyzed categorical variables using the $\chi^{2}$ test or Fisher's exact test. Comparisons of genotype distribution between groups were also performed using Fisher's exact test. Relations between two continuous variables were assessed by a bivariate correlation method (Pearson's correlation) Subsequently, significantly correlated variables were further analyzed using stepwise linear regression for multivariate analysis. The $P$-value was two sided. A $P$-value of $<0.05$ was considered statistically significant. The corrected $P(P c)$ value was adjusted using Bonferroni's correction. Statistical analysis was performed using SPSS software (Version 15.0, SPSS, Chicago, IL, USA).

\section{RESULTS}

\section{Demographic data on the patients}

A total of 92 patients took $50 \mathrm{mg}$ of HCTZ in our study. Of the patients, 2 did not have genotyping data available, and 15 did not have serum potassium levels tested after HCTZ treatment. The final 
a

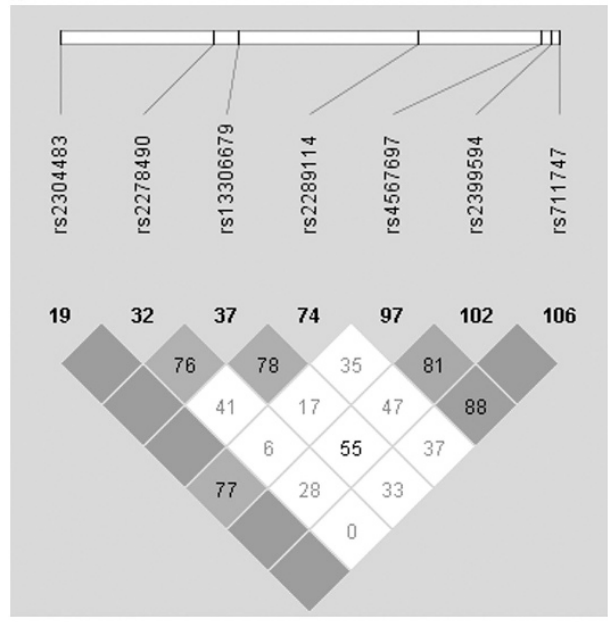

b

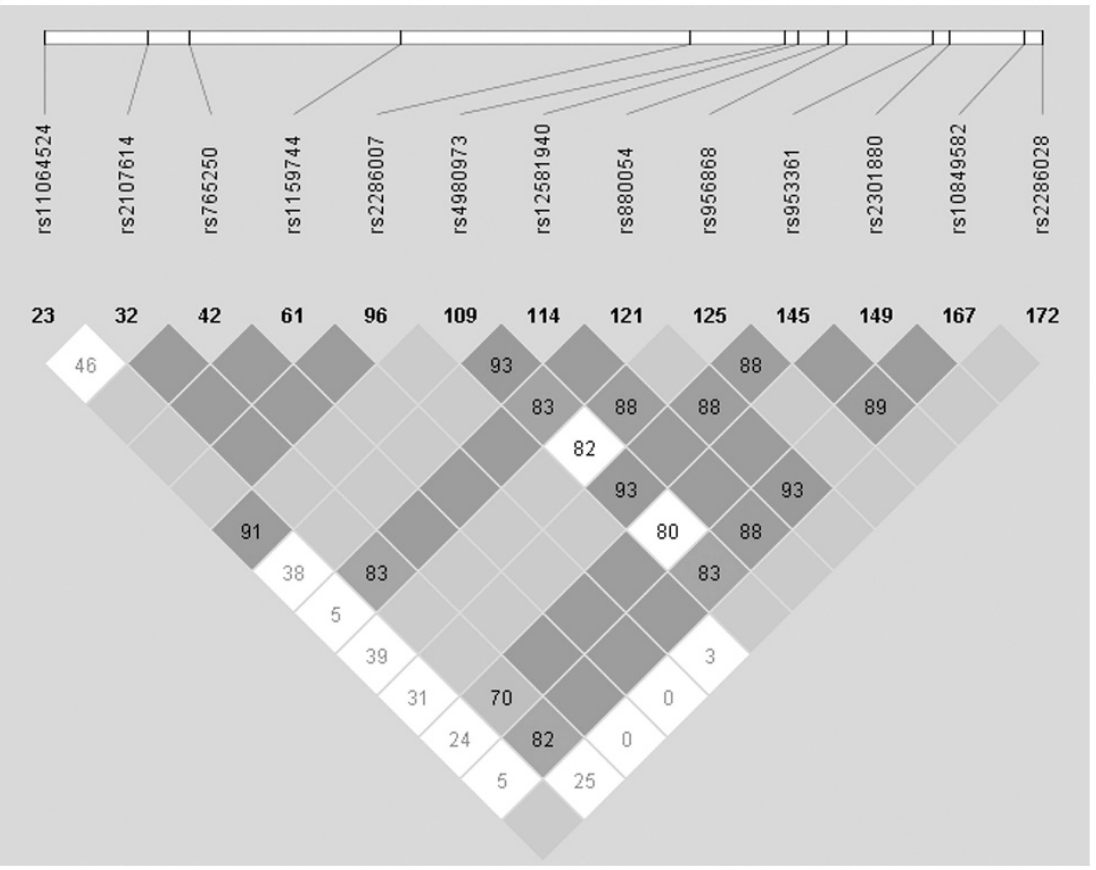

Figure 1 Haploview-generated linkage disequilibrium (LD) plot of (a) SLC12A3 single-nucleotide polymorphisms (SNPs) and (b) WNK1 SNPs. A full color version of this figure is available at the Hypertension Research journal online.

sample included 75 patients who qualified for enrollment in our study. The baseline characteristics of the patients are presented in Table 1. The mean age was $45.3 \pm 9.5$ years; 54 (72\%) patients were male. The mean SBP was $143.7 \pm 17.6 \mathrm{~mm} \mathrm{Hg}$ and the mean DBP was $96.0 \pm 9.4 \mathrm{~mm} \mathrm{Hg}$ (Table 1). The concomitant medications included $\beta$-blockers (62.7\%), $\alpha$-blockers (6.7\%), calcium channel blockers (30.7\%), angiotensin-converting enzyme inhibitors $(5.3 \%)$ and angiotensin receptor blockers (5.3\%) (Table 1).

\section{Response after 2 weeks of treatment with thiazide diuretics}

After a 2-week washout period, all the patients received HCTZ for 2 weeks. The patient responses to HCTZ are presented in Table 1. The mean SBP decreased from $141.4 \pm 13.8$ to $128.1 \pm 15.1 \mathrm{~mm} \mathrm{Hg}$ (net change, $-13.3 \pm 14.0 \mathrm{~mm} \mathrm{Hg}$ ). The mean DBP dropped from $94.2 \pm 7.8$ to $86.7 \pm 9.8 \mathrm{~mm} \mathrm{Hg}$ (net change, $-7.5 \pm 8.9 \mathrm{~mm} \mathrm{Hg}$ ). The mean potassium level declined from $4.3 \pm 0.3$ to $3.9 \pm 0.4 \mathrm{mmoll}^{-1}$ (net change, $-0.3 \pm 0.4 \mathrm{mmoll}^{-1}$ ). The mean sodium level was similar before and after 2 weeks of treatment with HCTZ (from $142.7 \pm 1.9$ to $142.8 \pm 1.8 \mathrm{mmoll}^{-1}$, net change $0.0 \pm 2.0 \mathrm{mmoll}^{-1}$ ).

Of all the demographic data considered, only baseline potassium was correlated with the decrease in serum potassium after 2 weeks of HCTZ treatment $(r=-0.423, P<0.001)$. The concomitant medications were not correlated with the decrease in serum potassium.

Serum potassium decrease after treatment with thiazide diuretics and the SNPs of the two candidate genes

Of the 13 SNPs in WNK1, rs11064524 $(P=0.040), \quad$ rs4980973 $(P=0.0007), \quad \operatorname{rs} 12581940 \quad(P=0.003), \quad \operatorname{rs} 880054 \quad(P=0.046)$, rs953361 $(P=0.003)$ and $\operatorname{rs} 10849582(P=0.046)$ were correlated with the decrease in serum potassium (Table 2). After Bonferroni's correction, only rs4980973 was correlated with the decrease in serum potassium $(P \mathrm{c}=0.014)$. Of the seven SNPs in SLC12A3, none was correlated with the serum potassium decrease in our study (Table 2).

\section{WNK1 rs4980973 polymorphism}

When comparing the serum potassium change associated with the WNK1 rs4980973 A/A, A/G and G/G polymorphisms, significant differences were observed (A/A vs. $\mathrm{A} / \mathrm{G}$ vs. $\mathrm{G} / \mathrm{G}=-0.45 \pm 0.42$ vs. $-0.46 \pm 0.37$ vs. $0.00 \pm 0.39 \mathrm{mmoll}^{-1}, P=0.0001$; Figure 2a). The office SBP change (A/A vs. $\mathrm{A} / \mathrm{G}$ vs. $\mathrm{G} / \mathrm{G}=-19.35 \pm 16.28$ vs. $-10.47 \pm 11.31$ vs. $-11.52 \pm 15.31 \mathrm{~mm} \mathrm{Hg}, \quad P=0.090)$ and office DBP change (A/A vs. A/G vs. $\mathrm{G} / \mathrm{G}=-8.74 \pm 11.04$ vs. $-6.84 \pm 7.67$ vs. $-6.55 \pm 9.54 \mathrm{~mm} \mathrm{Hg}, P=0.725)$ did not significantly differ among the three groups.

When comparing the serum potassium changes associated with the WNK1 rs4980973 (A/A and A/G) and G/G polymorphisms, significant differences were observed (A/A and $\mathrm{A} / \mathrm{G}$ vs. $\mathrm{G} / \mathrm{G}=-0.46 \pm 0.38$ vs. $-0.00 \pm 0.39 \mathrm{mmoll}^{-1}, P=0.00006$; Figure 2b). The office SBP change (A/A and $\mathrm{A} / \mathrm{G}$ vs. $\mathrm{G} / \mathrm{G}=-9.07 \pm 9.00$ vs. $-8.19 \pm$ $10.50 \mathrm{~mm} \mathrm{Hg}, P=0.740$ ) and office DBP change (A/A and A/G vs. $\mathrm{G} / \mathrm{G}=-7.83 \pm 9.36$ vs. $-6.42 \pm 10.87 \mathrm{~mm} \mathrm{Hg}, P=0.605)$ were not significantly different between the two groups.

Predictors of the decrease in serum potassium after treatment with thiazide diuretics

Finally, we included the serum potassium level and WNK1 rs4980973 in a multivariate stepwise regression analysis. Using multivariate stepwise linear regression analysis, the baseline potassium level $(\beta=-0.587, \quad 95 \%$ confidence interval $=-0.875$ to -0.299 , $P=0.0001$ ) and WNK1 rs4980973 (A/A and $\mathrm{A} / \mathrm{G}$ vs. $\mathrm{G} / \mathrm{G}$, $\beta=-0.418,95 \%$ confidence interval $=-0.598$ to -0.237 , $P=0.00002)$ were independent predictors of the decrease in serum potassium following HCTZ treatment (Table 3).

In this model, the baseline potassium level explained $14.9 \%$ and the WNK1 rs4980973 polymorphism explained $22.8 \%$ of the total variance in the decrease in serum potassium levels. Overall, $37.7 \%$ of the change in serum potassium levels could be explained by our model (Table 3). 
Table 1 Baseline characteristics of the patients and their response after 2 weeks of HCTZ

Total patients $(\mathrm{n}=75)$

\begin{tabular}{|c|c|}
\hline \multicolumn{2}{|l|}{ Baseline characteristics } \\
\hline Age, years & $45.3 \pm 9.5$ \\
\hline Onset, years & $38.6 \pm 10$ \\
\hline Male, $n(\%)$ & $54(72.0)$ \\
\hline BW, kg & $75.4 \pm 15$ \\
\hline Height, cm & $165.9 \pm 8.3$ \\
\hline BMI, $\mathrm{kg} \mathrm{m}^{-2}$ & $27.2 \pm 4.0$ \\
\hline Waist-hip ratio & $0.9 \pm 0.1$ \\
\hline SBP, mm Hg & $143.7 \pm 17$ \\
\hline DBP, mm Hg & $96.0 \pm 9.4$ \\
\hline $\mathrm{HR}$, beat per min & $75.3 \pm 12$ \\
\hline \multicolumn{2}{|l|}{ Concomitant medication } \\
\hline$\beta$-Blocker, $n$ (\%) & $47(62.7)$ \\
\hline$\alpha$-Blocker, $n(\%)$ & $5(6.7)$ \\
\hline $\mathrm{CCB}, n(\%)$ & $23(30.7)$ \\
\hline ACE inhibitor, $n(\%)$ & $4(5.3)$ \\
\hline ARB, $n(\%)$ & $4(5.3)$ \\
\hline
\end{tabular}

Washout periods

BW, kg

$\mathrm{SBP}, \mathrm{mm} \mathrm{Hg}$

DBP, $\mathrm{mm} \mathrm{Hg}$

$H R$, beat per min

BUN, mg dl ${ }^{-1}$

$\mathrm{Cr}, \mathrm{mg} \mathrm{dl}^{-1}$

$\mathrm{Na}, \mathrm{mmolI}^{-1}$

$\mathrm{K}, \mathrm{mmolI}^{-1}$

FBS, $\mathrm{mg} \mathrm{dl}^{-1}$

Cholesterol, $\mathrm{mgdl}^{-1}$

Triglyceride, $\mathrm{mgdl}^{-1}$

HDL-C, mg dl-1

LDL-C, mg dl ${ }^{-1}$

ALT, $\mathrm{UI}^{-1}$

AST, U I ${ }^{-1}$

Log PRA, ng ml-1 $\mathrm{h}^{-1}$

Log aldosterone, $\mathrm{pg} \mathrm{ml}^{-1}$

ACE activity, $\mathrm{ng} \mathrm{ml}^{-1}$

$76.1 \pm 15.5$

$141.4 \pm 13.8$

$94.2 \pm 7.8$

$78.6 \pm 14.9$

$13.2 \pm 4.9$

$0.9 \pm 0.2$

$142.7 \pm 1.9$

$4.3 \pm 0.3$

$97.5 \pm 13.8$

$201.8 \pm 39.7$

$166.1 \pm 104.1$

$45.0 \pm 12.1$

$122.5 \pm 32.2$

$41.1 \pm 30.0$

$26.6 \pm 13.9$

$0.76 \pm 0.51$

$2.17 \pm 0.20$

$130.39 \pm 33.19$

\section{After 2 weeks of HCTZ}

BW, kg

$75.3 \pm 14.9$

SBP, $\mathrm{mm} \mathrm{Hg}$

DBP, $\mathrm{mm} \mathrm{Hg}$

$128.1 \pm 15.1$

$86.7 \pm 9.8$

$76.8 \pm 14.4$

$\mathrm{HR}$, beat per min

$\mathrm{Na}, \mathrm{mmolI}^{-1}$

$142.8 \pm 1.8$

$\mathrm{K}, \mathrm{mmoll}^{-1}$

$3.9 \pm 0.4$

Abbreviations: ACE, angiotensin-converting enzyme; ALT, alanine aminotransferase; $\mathrm{ARB}$, angiotensin II receptor antagonist; AST, aspartate aminotransferase; BMI, body mass index; BUN, blood urine nitrogen; BW, body weight; CCB, calcium channel blocker; $\mathrm{Cr}$, creatinine; DBP, diastolic blood pressure; FBS, fasting blood sugar; HCTZ,

hydrochlorothiazide; HDL-C, high-density lipoprotein cholesterol; HR, heart rate; K, potassium;

LDL-C, low-density lipoprotein cholesterol; Na, sodium; PRA, plasma renin activity;

SBP, systolic blood pressure.

\section{DISCUSSION}

This study was designed to assess potential determinants of a serum potassium decrease following the short-term use of thiazide diuretics. The findings indicated that baseline potassium levels and the WNK1 rs4980973 polymorphism could predict the decrease in serum potassium following the use of thiazide diuretics. To our knowledge, ours is the first study to show that the WNK1 polymorphism can predict the decrease in serum potassium following the use of thiazide diuretics in nondiabetic hypertensive patients.

The use of thiazide diuretics increases urinary potassium excretion and lowers serum potassium levels. Because most potassium in the body is intracellular, the serum potassium concentration is tightly regulated. Therefore, frank hypokalemia (a serum potassium $<3.5 \mathrm{mmoll}^{-1}$ ) occurs only in cases of severe potassium depletion. ${ }^{21-23}$ However, hypokalemia is common in patients using thiazide diuretics. $^{8-11}$ A cross-sectional analysis of 22239 patients who presented to an emergency room in a university hospital in Switzerland ${ }^{8}$ found that the use of thiazide diuretics was associated with hypokalemia (odds ratio, $2.18, P<0.0001$ ). In a populationbased Rotterdam study, Liamis et al. ${ }^{6}$ reported that thiazide diuretics increased the risk of hypokalemia (odds ratio, 7.68; 95\% confidence interval, 4.92-11.98).

Moreover, accumulating evidence indicates that thiazide-induced hypokalemia is associated with adverse outcomes. In particular, there is concern about hypokalemic arrhythmias from thiazide use. ${ }^{7,24}$ Variation in the serum potassium level has also been implicated in the development and progression of coronary heart disease and myocardial infarction. ${ }^{24,25}$ Arampatzis et al. ${ }^{8}$ reported that the presence of hypokalemia on admission was associated with higher in-hospital mortality (odds ratio, 1.89; $P<0.0001$ ). ${ }^{8}$ Furthermore, thiazide-induced hypokalemia is associated with increased blood glucose values and an increased risk of new-onset diabetes mellitus. ${ }^{26,27}$

The WNK1 gene is located on chromosome 12 (12p13.3). It encodes a lysine-deficient protein kinase that regulates NCC in the luminal membrane of the distal convoluted tubule. ${ }^{17}$ Turner et al. ${ }^{20}$ investigated the change in $\mathrm{BP}$ in 585 adults with essential hypertension (30 to 59.9 years of age; $50 \%$ blacks; $47 \%$ women) after 4 weeks of HCTZ treatment ( $25 \mathrm{mg}$ daily). After adjusting for ethnicity, sex, age and waist-to-hip ratio, three SNPs in WNK1 (rs2107614, rs2277869 and rs1159744) predicted the ambulatory BP response, accounting for 2 to $4 \%$ of the variation in the systolic and diastolic BP response $(P<0.05)$. Polymorphisms in genes regulating renal sodium transport, in particular $W N K 1$, predict interindividual differences in antihypertensive responses to HCTZ. In the current study, we found that the WNK1 rs4980973 polymorphism could predict the change in serum potassium following use of thiazide diuretics, accounting for $22.8 \%$ of the total variance in the decrease in serum potassium levels. Because rs4980973 is located in the intron of the WNK1 gene, the polymorphism of this SNP may be involved in RNA splicing and stability. However, further replication studies or functional studies are needed to clarify the role of WNK1 in the regulation of potassium levels in patients taking thiazide diuretics.

The SLC12A3 gene is located on chromosome 16 (16q13). It encodes the NCC in the luminal membrane of the distal convoluted tubule. ${ }^{13,14}$ Mutations in the NCC have been reported to be the cause of Gitelman's syndrome, ${ }^{13-16}$ an autosomal recessive renal tubular disorder characterized by hypokalemia, metabolic alkalosis, hypomagnesemia and hypocalciuria. Matayoshi et al. ${ }^{28}$ reported that the SLC12A3 polymorphism could also predict the effects of thiazide diuretics. Comparison of the polymorphism prevalence between responders and nonresponders showed significant differences in SLC12A3 C1784T (C allele vs. T allele, odds ratio $=3.81$, confidence interval $=1.25-11.63, P=0.016)$. However, the association between $S L C 12 A 3$ and thiazide-induced hypokalemia is still unknown. In our study, we found that SLC12A3 polymorphisms were not related to the change in serum potassium level following the use of thiazide diuretics. 
Table 2 Association of individual SLC12A3 and WNK1 gene variants and serum potassium level change after HCTZ

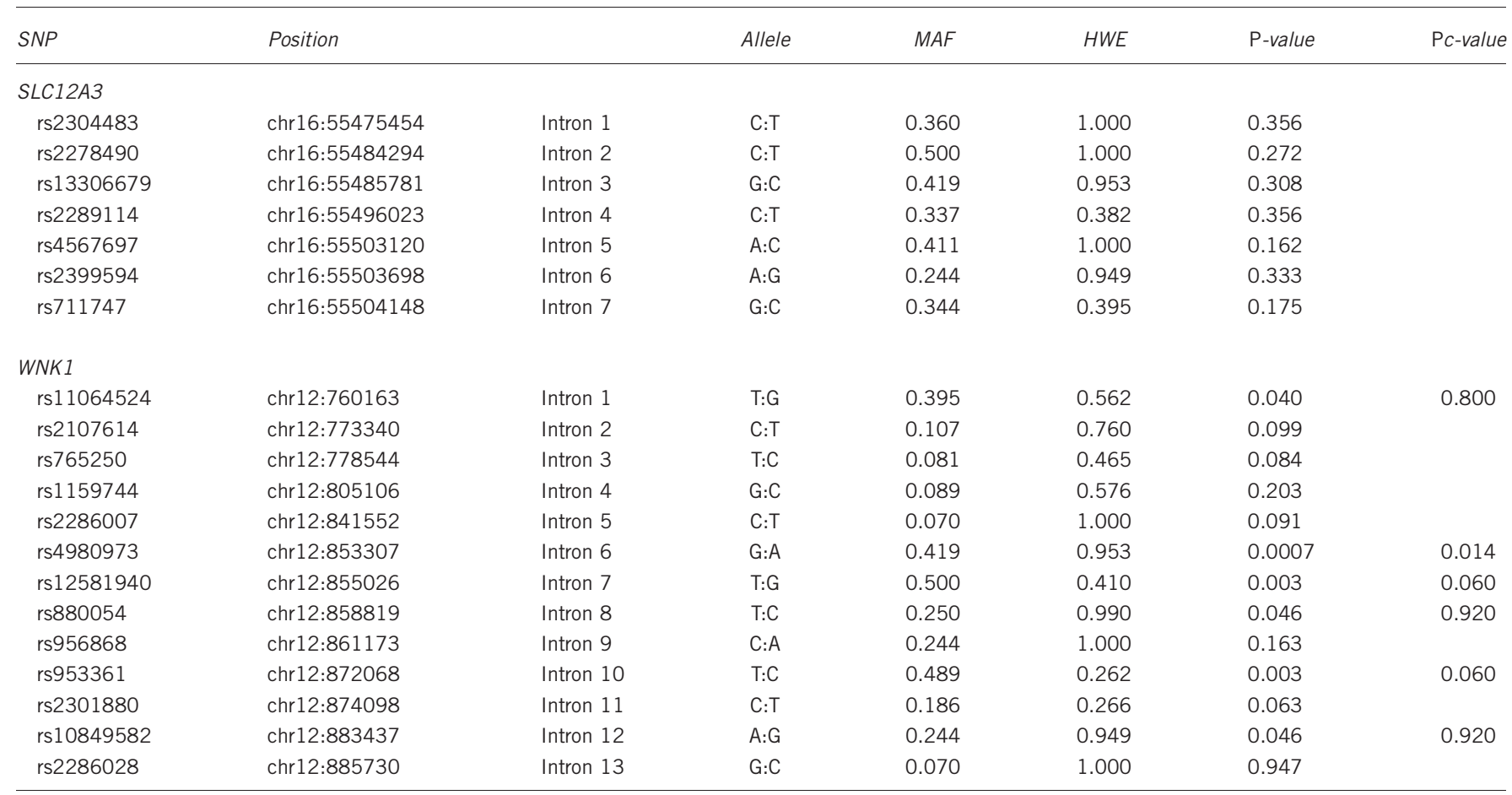

Abbreviations: HCTZ, hydrochlorothiazide; HWE, Hardy-Weinberg equilibrium; MAF, minor allele frequency; $P$ c-value, corrected $P$-value; SNP, single-nucleotide polymorphism. Alleles shown are major:minor.

a

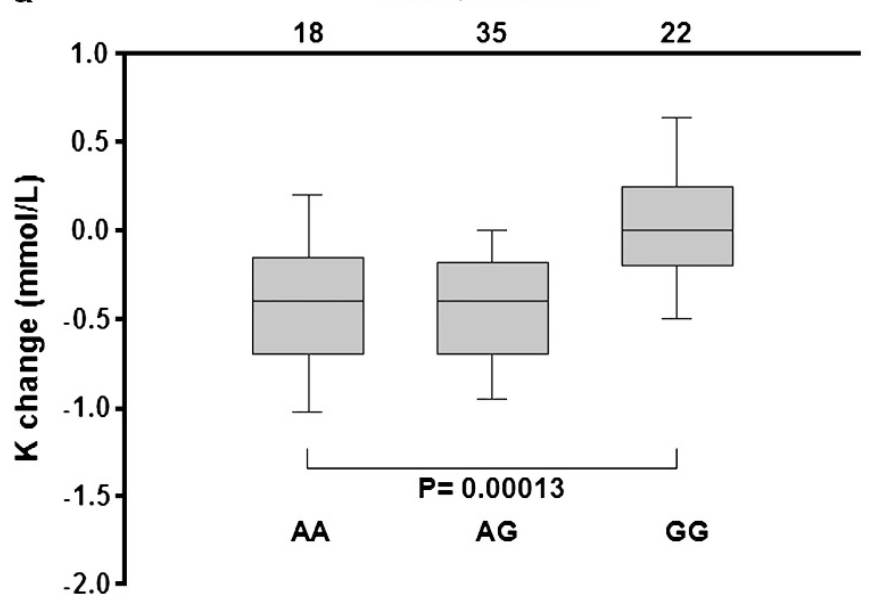

b

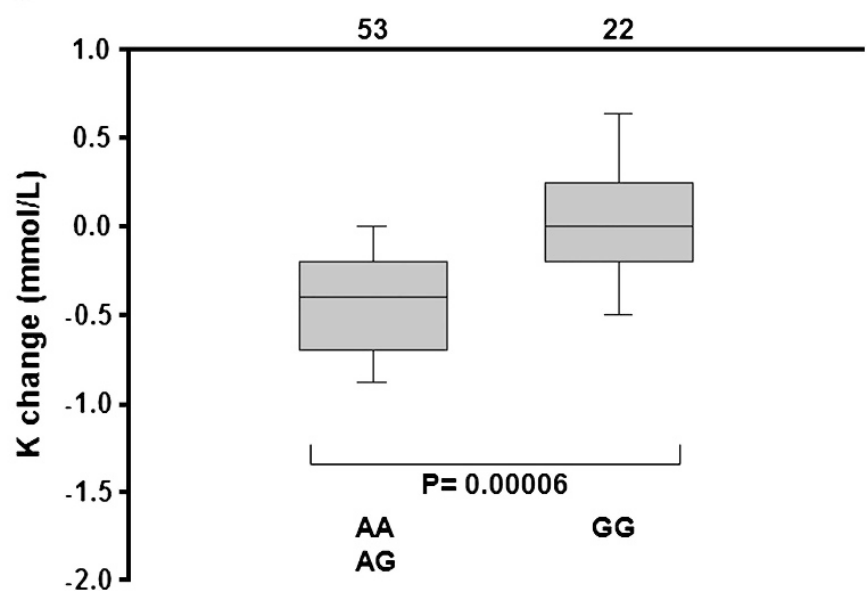

Figure 2 Serum potassium (K) level change was significantly different when comparing (a) WNK1 rs4980973 A/A $(n=18), A / G(n=35)$ and G/G polymorphisms ( $n=22)\left(\mathrm{A} / \mathrm{A}\right.$ vs. $\mathrm{A} / \mathrm{G}$ vs. $\mathrm{G} / \mathrm{G}=-0.45 \pm 0.42$ vs. $-0.46 \pm 0.37$ vs. $\left.0.00 \pm 0.39 \mathrm{mmol} \mathrm{I}^{-1}, P=0.0001\right)$, and (b) WNK1 rs4980973 (A/A and $\mathrm{A} / \mathrm{G})(n=53)$ and $\mathrm{G} / \mathrm{G}$ polymorphisms $(n=22)(\mathrm{A} / \mathrm{A}$ and $\mathrm{A} / \mathrm{G}$ vs. $\mathrm{G} / \mathrm{G}=-0.46)$.

Table 3 Clinical and genetic correlates of serum potassium level change: stepwise linear regression model $R^{2}=0.377$

\begin{tabular}{|c|c|c|c|c|}
\hline & Unstandardized coefficients $(\beta)$ & $95 \% \mathrm{Cl}$ & Partial $\mathrm{R}^{2}$ & P-value \\
\hline WNK1 rs4980973 (A/A and $A / G$ vs. G/G) & -0.418 & $(-0.598--0.237)$ & 0.228 & 0.00002 \\
\hline Baseline $\mathrm{K}, \mathrm{mmolI}^{-1}$ & -0.587 & $(-0.875--0.299)$ & 0.149 & 0.0001 \\
\hline
\end{tabular}

Abbreviations: $\beta$, unstandardized coefficient; $\mathrm{Cl}$, confidence interval; $\mathrm{K}$, potassium.

Abbreviations: $\beta$, unstandardized coefficient; $\mathrm{Cl}$, confidence interval; K, potassium.
Multivariate stepwise linear regression. Covariates into the model included baseline potassium level and WNK1 rs4980973 polymorphism.

Study limitations

Although the findings are interesting, the current study has some limitations worth noting. First, HCTZ was given for only 2 weeks.
However, we still found a change in serum potassium in these patients using thiazide diuretics in the short term. Second, the urine potassium level was not determined in this study. However, the daily 
intake was recommended to be maintained within a normal level in each patient before and during the study. Furthermore, we requested that the patients keep their daily lifestyle and eating habits the same before and during the 2 weeks of HCTZ treatment. Third, we analyzed the data of the 75 patients who completed the study. However, 15 patients had missing data. Fourth, some of our patients were on concomitant medications. However, we did not alter the concomitant medications before or after treatment with HCTZ. We found that the concomitant use of these medications (including angiotensin-converting enzyme inhibitors and angiotensin receptor blockers) was not correlated with the decrease in serum potassium after HCTZ treatment. Therefore, we did not exclude these cases from the study. Fifth, we enrolled patients aged 25 to 65 years (average $45.3 \pm 9.5$ years). The results of our study may therefore not apply to the aging population. Finally, our sample size was small and is limited to nondiabetic hypertensive patients in a Han Chinese population in Taiwan. Further replication or functional studies are needed to confirm the current findings.

\section{CONCLUSION}

Baseline potassium levels and the WNK1 rs4980973 polymorphism independently predicted the decrease in serum potassium after shortterm HCTZ treatment in nondiabetic hypertensive patients. Our findings provide additional information that may aid individualizing the use of thiazide diuretics and identifying hypertensive individuals at greater risk of a decrease in serum potassium.

\section{ACKNOWLEDGEMENTS}

We thank the technical/bioinformatics services provided by the National Center for Genome Medicine of the National Core Facility Program for Biotechnology, National Science Council. This work was partially supported by research grants V99B1-011, V99C1-125, V100B-013, V101B-004, V102B-024 and V103C-019 from Taipei Veterans General Hospital, Taipei, Taiwan; by research grants CI-97-13, CI-98-16 and CI-102-15 from the Yen Tjing Ling Medical Foundation, Taipei, Taiwan; by research grants NSC 100-2314-B-075055 and NSC 102-2314-B-075-022-MY3 from Taiwan's National Science Council, by a grant from Taiwan's Ministry of Education, the Aim for the Top University Plan and grants from Academia Sinica, Taipei, Taiwan, Republic of China. This study was also in part supported by the UST-UCSD International Center of Excellence in Advanced Bio-engineering sponsored by the Taiwan National Science Council I-RiCE Program under grant number NSC-99-2911I-009-101.

1 The ALLHAT Officers and Coordinators for the ALLHAT Collaborative Research Group Major outcomes in high-risk hypertensive patients randomized to angiotensin-converting enzyme inhibitor or calcium channel blocker vs diuretic: The Antihypertensive and Lipid-Lowering Treatment to Prevent Heart Attack Trial (ALLHAT). JAMA 2002; 288 2981-2997.

2 Treatment of Mild Hypertension Study Research Group. Treatment of Mild Hypertension Study. Final results. JAMA 1993; 270: 713-724.

3 SHEP Cooperative Research Group. Prevention of stroke by antihypertensive drug treatment in older persons with isolated systolic hypertension. Final results of the Systolic Hypertension in the Elderly Program (SHEP). JAMA 1991; 265: 3255-3264.

4 Chobanian AV, Bakris GL, Black HR, Cushman WC, Green LA, Izzo Jr. JL, Jones DW, Materson BJ, Oparil S, Wright Jr. JT, Roccella EJ, National Heart, Lung, and Blood Institute Joint National Committee on Prevention, Detection, Evaluation, and Treatment of High Blood Pressure; National High Blood Pressure Education Program Coordinating Committee. The seventh report of the Joint National Committee on Prevention, Detection, Evaluation, and Treatment of High Blood Pressure: the JNC 7 report. JAMA 2003; 289: 2560-2572.
5 Whitworth JA, World Health Organization, International Society of Hypertension Writing Group. 2003 World Health Organization (WHO)/International Society of Hypertension (ISH) statement on management of hypertension. J Hypertens 2003; 21: 1983-1992.

6 Liamis G, Rodenburg EM, Hofman A, Zietse R, Stricker BH, Hoorn EJ. Electrolyte disorders in community subjects: prevalence and risk factors. Am J Med 2013; 126 256-263.

7 Siegel D, Hulley SB, Black DM, Cheitlin MD, Sebastian A, Seeley DG, Hearst N, Fine R. Diuretics, serum and intracellular electrolyte levels, and ventricular arrhythmias in hypertensive men. JAMA 1992; 267: 1083-1089.

8 Arampatzis S, Funk GC, Leichtle AB, Fiedler GM, Schwarz C, Zimmermann H, Exadaktylos AK, Lindner G. Impact of diuretic therapy-associated electrolyte disorders present on admission to the emergency department: a cross-sectional analysis. BMC Medicine 2013; 11: 83

9 Halperin ML, Kamel KS. Potassium. Lancet 1998; 352: 135-140.

10 Ahmed A, Zannad F, Love TE, Tallaj J, Gheorghiade M, Ekundayo OJ, Pitt B. A propensity-matched study of the association of low serum potassium levels and mortality in chronic heart failure. Eur Heart J 2007; 28: 1334-1343.

11 Juurlink DN, Mamdani MM, Lee DS, Kopp A, Austin PC, Laupacis A, Redelmeier DA Rates of hyperkalemia after publication of the Randomized Aldactone Evaluation Study. New Engl J Med 2004; 351: 543-551.

12 Goyal A, Spertus JA, Gosch K, Venkitachalam L, Jones PG, Van den Berghe G, Kosiborod M. Serum potassium levels and mortality in acute myocardial infarction. JAMA 2012; 307: 157-164.

13 Simon DB, Nelson-Williams C, Bia MJ, Ellison D, Karet FE, Molina AM, Vaara I, Iwata F, Cushner HM, Koolen M, Gainza FJ, Gitleman HJ, Lifton RP. Gitelman's variant of Bartter's syndrome, inherited hypokalaemic alkalosis, is caused by mutations in the thiazide-sensitive Na-Cl cotransporter. Nat Genet 1996; 12: 24-30.

14 Mastroianni N, Bettinelli A, Bianchetti M, Colussi G, De Fusco M, Sereni F, Ballabio A, Casari G. Novel molecular variants of the $\mathrm{Na}-\mathrm{Cl}$ cotransporter gene are responsible for Gitelman syndrome. Am J Hum Genet 1996; 59: 1019-1026.

15 Lemmink HH, Knoers NV, Károlyi L, van Dijk $H$, Niaudet $P$, Antignac C, Guay-Woodford LM, Goodyer PR, Carel JC, Hermes A, Seyberth HW, Monnens LA, van den Heuvel LP. Novel mutations in the thiazide-sensitive $\mathrm{NaCl}$ cotransporter gene in patients with Gitelman syndrome with predominant localization to the C-terminal domain. Kidney Int 1998; 54: 720-730.

16 Lin SH, Cheng NL, Hsu YJ, Halperin ML. Intrafamilial phenotype variability in patients with Gitelman syndrome having the same mutations in their thiazide-sensitive sodium chloride cotransporter. Am J Kidney Dis 2004; 43: 304-312.

17 Wilson FH, Disse-Nicodème S, Choate KA, Ishikawa K, Nelson-Williams C, Desitter I, Gunel M, Milford DV, Lipkin GW, Achard JM, Feely MP, Dussol B, Berland Y, Unwin RJ, Mayan H, Simon DB, Farfel Z, Jeunemaitre X, Lifton RP. Human hypertension caused by mutations in WNK kinases. Science 2001; 293: 1107-1112.

18 Kathiresan S, Larson MG, Benjamin EJ, Corey D, Murabito JM, Fox CS, Wilson PW, Rifai N, Meigs JB, Ricken G, Lifton RP, Levy D, Vasan RS. Clinical and genetic correlates of serum aldosterone in the community: the Framingham Heart Study. Am J Hypertens 2005; 18: 657-665.

19 Kessler SP, Rowe TM, Gomos JB, Kessler PM, Sen GC. Physiological non-equivalence of the two isoforms of angiotensin-converting enzyme. J Biol Chem 2000; 275: 26259-26264

20 Turner ST, Schwartz GL, Chapman AB, Boerwinkle E. WNK1 kinase polymorphism and blood pressure response to a thiazide diuretic. Hypertension 2005; 46: 758-765.

21 Gorden P. Glucose intolerance with hypokalemia. Failure of short-term potassium depletion in normal subjects to reproduce the glucose and insulin abnormalities of clinical hypokalemia. Diabetes 1973; 22: 544-551.

22 Rowe JW, Tobin JD, Rosa RM, Andres R. Effect of experimental potassium deficiency on glucose and insulin metabolism. Metabolism 1980; 29: 498-502.

23 Siscovick DS, Raghunathan TE, Psaty BM, Koepsell TD, Wicklund KG, Lin X, Cobb L, Rautaharju PM, Copass MK, Wagner EH. Diuretic therapy for hypertension and the risk of primary cardiac arrest. New Engl J Med 1994; 330: 1852-1857.

24 Salvetti A, Ghiadoni L. Thiazide diuretics in the treatment of hypertension: an update. J Am Soc Nephrol 2006; 17: S25-S29.

25 Franse LV, Pahor M, Di Bari M, Somes GW, Cushman WC, Applegate WB. Hypokalemia associated with diuretic use and cardiovascular events in the systolic hypertension in the elderly program. Hypertension 2000; 35: 1025-1030.

26 Zillich AJ, Garg J, Basu S, Bakris GL, Carter BL. Thiazide diuretics, potassium, and the development of diabetes: a quantitative review. Hypertension 2006; 48: 219-224.

27 Carter BL, Einhorn PT, Brands M, He J, Cutler JA, Whelton PK, Bakris GL, Brancati FL, Cushman WC, Oparil S, Wright Jr. JT, Working Group from the National Heart, Lung, and Blood Institute. Thiazide-induced dysglycemia: call for research from a working group from the national heart, lung, and blood institute. Hypertension 2008; 52: $30-36$.

28 Matayoshi T, Kamide K, Takiuchi S, Yoshii M, Miwa Y, Takami Y, Tanaka C, Banno M, Horio T, Nakamura S, Nakahama H, Yoshihara F, Inenaga T, Miyata T, Kawano Y. The thiazide-sensitive $\mathrm{Na}(+)-\mathrm{Cl}(-)$ cotransporter gene, C1784T, and adrenergic receptorbeta3 gene, T727C, may be gene polymorphisms susceptible to the antihypertensive effect of thiazide diuretics. Hypertens Res 2004; 27: 821-833. 